\title{
MULHER NÃO DEVIA TER REGIMENTO: RAINHAS REGENTES, RAINHAS DEPOSTAS (PORTUGAL, SÉC. XIV-XV)
}

\section{Women should not have a regiment: regent queens, deposed queens (Portugal, 14th-15th centuries)}

\author{
Prof. Dra. Miriam Coser \\ Professora Doutora Associada do Departamento de História e do Programa de Pós- Graduação \\ em História da Universidade Federal do Estado do Rio de Janeiro (UNIRIO) \\ E-mail: miriamcoser@yahoo.com.br \\ ORCID: https://orcid.org/0000-0001-6931-5025
}

\begin{abstract}
Resumo : Ao longo da Idade Média portuguesa, duas rainhas foram legitimamente designadas regentes e ambas acabaram depostas por opositores. O direito de regência de Leonor Teles, em caso de morte do rei D. Fernando, foi estabelecido no Tratado de Salvaterra de Magos, mas os acontecimentos que a historiografia convencionou chamar de Revolução de Avis (1383-1385) levaram à deposição de Leonor, seu confinamento no convento de Santa Clara em Tordesilhas e ao estabelecimento de uma nova dinastia com a aclamação do filho ilegítimo de D. Pedro, D. João I, o Mestre de Avis. O direito de regência de Leonor de Aragão em caso de falecimento do rei D. Duarte foi estabelecido no próprio testamento deste. Também nesse caso, a rainha regente foi deposta pelo irmão do rei morto, D. Pedro, em 1439, fazendo com que Leonor de Aragão se visse em seguida forçada a abandonar seus filhos e fugir para Castela, levando apenas uma das crianças, ainda lactante. Nas Cortes de Lisboa, que sacramentaram a deposição de Leonor de Aragão, o Jurista Diogo Afonso Mangancha teria argumentado que molher nom devia ter regimento. Este artigo propõe analisar o discurso sobre a fraqueza feminina como impedimento dessas regências nas narrativas dos cronistas da Casa de Avis.
\end{abstract}

Palavras-chave: crônicas, regências, rainhas.

Abstract : Throughout Middle Ages in Portugal, two queens were legitimately designated as regents and both were deposed by opponents. If King Fernando died, Leonor Teles would be the regent of Portugal, as it was established in the Salvaterra de Magos Treaty. Nevertheless, the events that historiography conventionally called the Avis Revolution (1383-1385) led to the deposition of Leonor, her confinement in the convent of Santa Clara in Tordesillas and the establishment of a new dynasty with the acclamation of the illegitimate son of D. Pedro, D. João I, the Master of Avis. If King Duarte died, Leonor de Arragon, as well, would be regent of the reign, as it was written in the king's will. In this case too, the regent queen was deposed by the brother of the dead king, D. Pedro, in 1439. Leonor de Aragon was forced to abandon most of her children and flee to Castile, taking only one of them with her, a still lactating child. In the Lisbon courts, which decided the deposition of Leonor de Aragon, the jurist Diogo Afonso Mangancha argued that women should not be regents. This article proposes to analyze the discourse about female weakness as an impediment to these regencies in the narratives of the chroniclers of the Avis dynasty.

Keywords: chronicles, regencies, queens. 


\section{Introdução}

Ao longo da Idade Média portuguesa, duas rainhas foram legitimamente designadas regentes e ambas acabaram depostas por opositores. $\mathrm{O}$ direito de regência de Leonor Teles, em caso de morte do rei D. Fernando, foi estabelecido no Tratado de Salvaterra de Magos, que determinava que a rainha Leonor Teles seria a única regente do reino português, caso o rei morresse antes que sua filha Beatriz, casada com o rei de Castela D. Juan, tivesse um filho em idade de governar. Nesse sentido, a regência de Leonor só cessaria quando essa condição fosse cumprida: um legítimo herdeiro atingisse a idade de catorze anos. Entretanto, os acontecimentos que a historiografia convencionou chamar de Revolução de Avis (1383-1385) levaram à deposição de Leonor, seu confinamento no convento de Santa Clara em Tordesilhas e ao estabelecimento de uma nova dinastia com a aclamação do filho ilegítimo de D. Pedro, João I, o Mestre de Avis. O direito de regência de Leonor de Aragão em caso de falecimento do rei D. Duarte foi estabelecido no próprio testamento deste. O documento determinava explicitamente que Leonor de Aragão regeria sozinha o reino português até que seu filho Afonso atingisse a idade para governar. Mais do que isso, o testamento determinava também que a rainha seria a tutora de seus filhos. Também nesse caso, a rainha regente foi deposta pelo irmão do rei morto, o infante D. Pedro, em 1439, fazendo com que Leonor de Aragão se visse em seguida forçada a abandonar seus filhos e fugir para Castela, levando apenas uma das crianças, ainda lactante.

O estudo dessas regências femininas em Portugal encontra dificuldades na medida em que a documentação disponível sobre elas é escassa, de forma que a maior parte das informações disponíveis é resultante das crônicas do reino, que, como é sabido, foram escritas de forma a legitimar e exaltar a dinastia de Avis. Além das intempéries habituais que qualquer documentação histórica sofre, Ana Maria Rodrigues aponta para o fato de que a documentação referente às rainhas é ainda mais escassa do que a referente aos reis, uma vez que não há livros de compilação dos atos das rainhas a exemplo dos livros de chancelarias reais. No entanto, as rainhas emitiam alvarás, cartas e sentenças, que se perderam ou encontram-se dispersos em diversos arquivos. Provavelmente, tal situação foi agravada com a reforma efetuada a partir de 1458 pelo cronista real e Guarda Mor da Torre do Tombo, Gomes Eanes de Zurara, que descartou documentos não considerados dignos de memória ao compilar a documentação em novos suportes. Soma-se a isso o 
fato de que os opositores dessas rainhas depostas talvez tenham destruído determinados documentos, como pode ter sido o caso do testamento de D. Duarte, que não chegou a nossos dias (Rodrigues, 2013: p.109).

O resultado desse panorama documental é a tendência de nos fiarmos nos registros das crônicas reais não apenas ao tentarmos identificar os fatos que pontuaram esses processos de regência e deposição, mas também ao avaliarmos as motivações de tais deposições de regentes femininas. Não raro se atribui - para além das intricadas relações políticas da nobreza portuguesa e de suas relações com as principais cidades do reino, em especial Lisboa - à misoginia medieval o fracasso das regências femininas em Portugal. A crença na natural fraqueza feminina compartilhada pelos homens (e mulheres) na Idade Média seria um dos motores dessa reação ao governo das rainhas. Entretanto, tal crença não impediu o exercício do pleno queenship por parte de diversas rainhas ao longo do período medieval na Europa Ocidental de uma maneira geral e na Península Ibérica de forma mais específica.

Diante desse desafio, propomos aqui uma reflexão sobre o lugar da "fraqueza feminina" como explicação para a deposição das rainhas regentes portuguesas no próprio discurso dos cronistas medievais que se dedicaram a narrar tais episódios. Os acontecimentos relativos à Leonor Teles foram tratados por Fernão Lopes na Crônica de D. Fernando e na Crônica de D. João I. Já os episódios que envolveram Leonor de Aragão foram narrados por Rui de Pina na Crônica de D. Duarte e na Crônica de D. Afonso $V$. Antes de nos determos na análise dessas crônicas, será feita uma breve contextualização desses dois períodos regenciais.

\section{A regência da rainha Leonor Teles}

A linhagem de Leonor Teles de Meseses $^{1}$ remetia ao rei Fruela II das Astúrias e Leão, por parte de pai, e ao rei D. Sancho I de Portugal, por parte de mãe. Leonor nasceu por volta de 1350, provavelmente em Tras-os-Montes, apesar de não haver unanimidade entre os historiadores a esse respeito (Oliveira, 2010: p.307). Era filha de Martim Afonso Teles de Meneses que foi mordomo mor da rainha D. Maria de Portugal esposa do rei Afonso XI de Castela. Sua mãe, Aldonça Anes de Vasconcelos, tinha como trisavó Teresa Sanches, filha ilegítima de D. Sancho I. Leonor Teles viria a casar-se com 
D. Fernando, rei de Portugal, que descendia por linhagem paterna também de D. Sancho I.

Após a morte dos pais - a mãe devido à peste e o pai assassinado por D. Pedro de Castela que se rebelara contra a própria mãe, D. Maria de Portugal - Leonor e seus irmãos (João Afonso, Gonçalo e Maria) foram criados pelos tios João Afonso Teles, conde de Barcelos, e Guiomar Lopes. Casou muito jovem com João Lourenço da Cunha, senhor do Pombeiro, de quem teve um filho, Álvaro da Cunha. É digno de nota o fato de que o marido de Leonor era vassalo de D. João, filho de Inês de Castro e meio irmão do rei D. Fernando. Essas relações de lealdade seriam importantes nas configurações políticas do reino.

Em 1371, Leonor Teles chegou ao paço português para visitar a irmã e conheceu o rei, com quem se casou publicamente no ano seguinte. A anulação de seu casamento anterior foi provavelmente providenciada com alegação de parentesco e seu filho criado por outro casal. Em 1373, nasceu a única filha do casal real que sobreviveria, Beatriz.

O casamento de Leonor e Fernando levou à anulação do Tratado de Alcoutim, que previa não apenas a paz com Castela, como também o casamento de D. Fernando com a filha do rei castelhano. A guerra entre os dois reinos vizinhos havia sido motivada pela tomada do trono de Castela por Henrique II, senhor da Trastâmara, que assassinara seu meio irmão Pedro, filho de Maria de Portugal. O Tratado de paz traria a vantagem da anexação de novos territórios ao reino português, advindos do casamento, mas por outro lado colocava D. Fernando fortemente ligado a Henrique II. Por essas razões, historiadores divergem quanto a uma possível intencionalidade política ou mera impulsividade como explicação do casamento de Fernando com Leonor. (Matoso; Ssousa, 1992: p. 492).

Posteriormente, o reinado de D. Fernando ainda passaria por mais dois conflitos com Castela, imbricados no quadro da Guerra dos Cem Anos. Nos períodos de guerra com o reino vizinho, D. Fernando procurou o apoio inglês, uma vez que o duque de Lancaster reivindicava o trono castelhano em virtude de seu casamento com Constança, filha do rei D. Pedro I de Castela. É nesse contexto que o conde de Ourém, João Fernandes Andeiro, passa a desempenhar um papel importante na política portuguesa, intercedendo pela Inglaterra e tornando-se um aliado de Leonor. No entanto, nos momentos de paz a aproximação era com a França, aliada de Castela. O Grande Cisma 
da Igreja tornava ainda mais complexa a situação, pois o reino português, de acordo com a aproximação com a Inglaterra ou a França, reconhecia o papa de Roma ou o de Avignon. Somava-se a isso o panorama de pestes e crises de abastecimento, o que gerava muitas insatisfações.

D. Fernando morreu logo após mais um acordo com Castela, o Tratado de Salvaterra de Magos. O tratado previa o casamento de sua filha Beatriz com o então rei de Castela, D. Juan I, filho do falecido D. Henrique II. Previa igualmente a regência de Leonor Teles em caso de morte do rei português, até que um herdeiro completasse catorze anos. Beatriz tinha apenas 11 anos e já havia passado por diversos acordos de casamento, mas este último se concretizou.

Após a morte do rei, em 1383, Leonor Teles inicia sua regência e assume a administração do reino. A rainha, que antes da morte de D. Fernando assinava como "Dona Leonor pela graça de Santa Maria rainha de Portugal e Algarve", passa a assinar "Dona Leonor pela graça de Deus rainha e governadora e regedora dos reinos de Portugal e Algarve", numa clara demonstração da ampliação de seus poderes no plano divino e terrestre. Da mesma forma, procura assegurar os direitos de sua filha Beatriz fazendo com que as cidades tomassem voz pela rainha menina, levando pendão e a saudando, como era costume fazer após a morte de um rei pra a aclamação do herdeiro.

Entretanto, a morte de D. Fernando fez com que seus meio irmãos, assim como o rei de Castela, casado com Beatriz, aspirassem ao trono português. D. Juan I de Castela, ciente da disputa, mandou prender os filhos de D. Pedro e Inês de Castro que estavam em solo castelhano. Restou em Portugal apenas o filho de D. Pedro com Teresa Lourenço, D. João, o Mestre de Avis. Os protagonistas da disputa pelo trono entre 1383 e 1385 serão, portanto, Leonor Teles, D. Juan I e D. João.

O estopim que desencadeou os conflitos foi o assassinato do conde Andeiro, principal aliado de Leonor, pelo Mestre de Avis e seus companheiros. A cidade de Lisboa foi então palco de conflitos generalizados e a Rainha parte para Alemquer, de onde procura organizar sua resistência. Recebeu ainda uma proposta de casamento por parte de D. João, o Mestre de Avis, que seria uma forma de contemporizar a revolta. Leonor recusa e insiste em seus direitos como regente, seguindo para Santarém. De lá, pede o apoio do rei de Castela para recuperar seus direitos. O rei castelhano atende o chamado, mas obtém de Leonor a desistência da regência do reino em seu favor. Logo 
ficaria claro para a rainha que havia perdido todas as suas prerrogativas e tenta ainda sublevar-se contra o rei castelhano, mas é presa por este e enviada para Tordesilhas, tendo morrido algum tempo depois, por volta de 1405 .

O desenrolar dos acontecimentos em Portugal, como é bem sabido, levaram ao reinado do Mestre de Avis, dando início a uma nova dinastia que teria como segundo rei seu filho D. Duarte.

\section{A regência da rainha Leonor de Aragão}

Leonor de $\operatorname{Aragão}^{2}$ nasceu provavelmente em Castela, mas é difícil estimar a data de nascimento. Já nasceu ligada por laços de sangue aos três reinos ibéricos que seriam determinantes na sua vida. Seu pai, D. Fernando de Aragão, era filho do rei de Castela, D. Juan e foi co-regente de Castela antes de ser rei de Aragão. Sua mãe, também chamada Leonor, era filha do conde de Albuquerque, D. Sancho Afonso (por sua vez, filho ilegítimo do rei Afonso XI de Castela) e de Beatriz de Portugal (por sua vez filha do rei português D. Pedro com Inês de Castro). Sua linhagem, portanto, ligava-a a reis de Castela, Aragão e Portugal. Leonor, que era bisneta do rei D. Pedro de Portugal, veio a casar-se com D. Duarte, que era neto do mesmo rei. Tais fatos não eram excepcionais no quadro de casamentos e alianças dinásticas da nobreza medieval e seu casamento com aquele que viria a ser rei de Portugal confirmava a paz estabelecida por este reino com Castela e permitia igualmente boas relações com Aragão.

Os irmãos e a irmã de Leonor também tiveram grande protagonismo nos reinos ibéricos. Afonso, que sucederia seu pai no trono de Aragão, casa com Maria, irmã do rei D. Juan II de Castela. João casa com a herdeira de Navarra e se torna rei deste reino. Henrique casa com Catarina, também irmã de D. Juan II de Castela. Sua irmã Maria casa com o próprio D. Juan II de Castela. Além dessa grande influência na Península Ibérica, seus irmãos tiveram pretensões também na Itália, em especial em Nápoles. As relações dos irmãos de Leonor com o reino de Castela, no entanto, oscilavam apesar de todos esses vínculos matrimoniais firmados. A rivalidade com o condestável de Castela, D. Álvaro de Luna, fortemente ligado ao rei, levava à alternância de momentos de tensão, e mesmo hostilidade aberta, a momentos de convivência pacífica e influência nos assuntos do reino castelhano. 
Leonor de Aragão chegou a Portugal justamente num momento de tensão entre Castela e Aragão e seu traslado foi pontuado por rivalidades entre as comitivas castelhanas e aragonesas. Seu casamento com D. Duarte ocorreu quando este ainda não era rei, mas já estava associado ao governo de D. João I, o Mestre de Avis. Chegando a Portugal, constituiu Casa, cabendo-lhe a jurisdição sobre determinadas terras. A afeição de D. Duarte pela esposa ficou registrada ao dedicar seu livro O Leal Conselheiro à rainha. Ao longo de seu casamento, antes e depois de ter se tornado rainha, gerou nove crianças, sendo que seis sobreviveram à primeira infância, inclusive o que se tornaria rei, D. Afonso.

Durante o reinado de D. Duarte, as relações entre Castela e Aragão estavam estáveis, entretanto, a morte prematura do rei português - vitimado pela peste em 1438 ocorre justamente no momento em que a nobreza aliada aos irmãos de Leonor em Castela perdia novamente terreno para seus opositores ligados a Álvaro de Luna, que exercia sua ascendência sobre o rei D. Juan II. Para além dos conflitos de seus irmãos em Castela, estes também sofriam revezes na Itália, ocorrendo, inclusive, a morte de seu irmão mais novo, Pedro. É neste contexto que se inicia a regência de Leonor, que estava grávida de sua última filha e logo ficaria de luto pela perda de outra filha.

Uma série de assuntos pendentes precisavam ser resolvidos, dentre eles a situação do infante D. Fernando, irmão do rei D. Duarte, que ainda estava preso em Fez. O infante havia sido capturado na tentativa de tomada de Tânger e o preço do resgate exigido era a entrega de Ceuta por parte do reino português. A rainha precisava reunir o Conselho e deliberar sobre o assunto, que envolvia inclusive a interferência do papa, contrário à entrega de Ceuta para os muçulmanos. Somava-se a isso o fato de que uma delegação de embaixadores de Castela aguardava para ser atendida, pois havia chegado justamente na ocasião da morte do rei.

A solução desses e de outros problemas exigia a colaboração dos irmãos de D. Duarte, os infantes D. Pedro, D. Henrique e D. João. As relações com o infante D. Pedro eram especialmente difíceis, em parte por este ser casado com a filha de Jaume de Urgel, que havia sido derrotado pelo pai de Leonor na disputa pelo trono de Aragão. Uma vez que as alianças de casamento eram um dos principais mecanismos de manutenção de boas relações políticas, a regente propõe a D. Pedro que realizassem o casamento dos primos D. Afonso V, filho de Leonor, e Isabel, filha de D. Pedro. 
Entretanto, era preciso contemporizar também com o meio irmão dos infantes, Afonso, filho ilegítimo de D. João I e conde Barcelos. O conde, que viria a ser um dos principais aliados de Leonor, também intencionava que uma neta sua viesse a se casar com o rei de Portugal. A regente acaba tendendo mais ao conde e torna-se reticente com relação ao acordo com D. Pedro.

A confirmação da regência de Leonor ocorreu nas Cortes de Torres Novas, dois meses após a morte do rei D. Duarte, juntamente com o reconhecimento e prestação de obediência ao rei D. Afonso $\mathrm{V}$, que tinha apenas seis anos. Leonor recebeu o apoio de grande parte da nobreza, notadamente o conde de Barcelos, e do arcebispo de Lisboa, que era seu primo. No entanto uma parte da nobreza e do clero estava sob a liderança de D. Pedro, que contava também com o apoio dos mesteirais de Lisboa. A regência de Leonor foi então garantida com uma proposta conciliatória de D. Henrique. A regente ficava responsável pela administração das rendas e ofícios, além de continuar tutora dos filhos; D. Pedro ficava responsável pela defesa do reino e D. Fernando, o conde de Arraiolos, associado a um grupo de conselheiros, ficava responsável pela justiça. A proposta de D. Henrique procurou contemplar de alguma forma seu irmão D. Pedro, a rainha Leonor e o conde de Barcelos, D. Afonso, que era pai do conde de Arraiolos.

Mesmo com a redução de seus poderes, a rainha permaneceu na regência e deu continuidade às suas atividades administrativas. A manutenção do funcionamento de sua Casa, incluindo as terras da rainha, que reunia diversos funcionários e requeria a cobrança de impostos e imposição da justiça, permitia a familiaridade com uma série de atribuições que precisava exercer como regente. Uma das medidas foi a reafirmação da cobrança de uma taxa aos mercadores da cidade de Lisboa, a ser paga a um de seus apoiadores. Tal ato serviu de estopim para que os mercadores se voltassem contra a rainha e no desenrolar dos episódios ficou evidente a ascendência de D. Pedro na cidade. A partir desse momento, ficava declarada a oposição entre a regente e o infante, que buscaram suas respectivas alianças e fizeram os preparativos para um conflito armado.

Leonor organizou sua resistência em suas terras de Alenquer, mas D. Pedro foi em seguida aclamado defensor e regedor do reino em Lisboa, antes mesmo da realização das cortes. A rainha, apesar de não aceitar a renúncia, acabou por acompanhar o filho 
para que o rei estivesse presente nas cortes, que acabaram por destituí-la da regência do reino. O golpe final foi a perda do poder de tutela sobre os filhos.

A rainha segue para Sintra, ainda esperando contar com os apoios dos irmãos, que, por seu turno, passavam por dificuldades em Castela e só enviaram embaixadas no intuito de interpelar D. Pedro. Este se aliava justamente aos opositores dos infantes de Aragão em Castela. Ainda decidida a resistir, Leonor segue para o Crato e espera obter ajuda especialmente do conde de Barcelos. Entretanto, ao saber da superioridade numérica dos exércitos de D. Pedro, já pronto para cercar o Crato, a rainha parte com membros de sua corte para Castela em 1440.

Mais uma vez, a rainha ainda procura obter apoio, dessa vez de sua irmã, rainha de Castela. Porém, a tensão entre o rei D. Juan II e os infantes de Aragão estava prestes a levar a mais conflitos armados e Leonor viu-se na tentativa de conciliar os ânimos pra finalmente poder obter apoio para a sua retomada da regência em Portugal. Uma primeira vitória dos irmãos de Leonor, com a expulsão do condestável de Castela, acabou resultado num ataque por parte dos portugueses. Em 1442, as cortes de Évora acusam Leonor de ter incitado estrangeiros a guerrear com Portugal e confisca todos os bens e rendas da Casa da rainha, além de proibi-la de voltar ao reino português.

Leonor de Aragão recorreu ainda às cortes de Valladolid, mas seu apoio era cada vez mais escasso. Finalmente, dispensou parte de sua corte e instalou-se em Toledo, de onde procurou obter permissão para retornar a Portugal. Mesmo capitulando e submetendo-se a D. Pedro, continuou proibida de voltar ao reino e acabou por morrer nessa cidade, de causas não esclarecidas, em 1445.

\section{A fraqueza feminina e a regência das rainhas}

A forma como a rainha Leonor Teles foi caracterizada nas crônicas de Fernão Lopes é bem conhecida: bela, sedutora, ardilosa e adúltera. O primeiro cronista oficial do reino português e guarda mor da Torre do Tombo influenciou gerações de historiadores que identificaram a rainha como a grande responsável pelos erros de D. Fernando e pela perda de sua própria regência. A intenção aqui não é buscar uma mulher real por traz da narrativa de Lopes, mas sim procurar compreender em que medida o 
discurso $^{3}$ de uma natureza feminina frágil e deficitária seria veiculado pelo cronista ao narrar o desenrolar dos acontecimentos que levaram à deposição de Leonor Teles.

Além das qualidades acima referidas, o cronista enfatiza dois aspectos que considera intrínsecos da personagem que constrói: a firme vontade e a coragem. Ao longo da Crônica de D. Fernando ${ }^{4}$, a afirmação da vontade de Leonor é pontuada nas diversas tramas que vão se desenrolando. Sabendo que seu casamento com o rei não era bem aceito por alguns do reino, manda investigar quem seriam seus principais opositores e "havia com o rei que os mandasse prender e fazer neles justiça." (Lopes, [s/d]: p.214). Sua ascendência sobre o rei era fruto de comentário entre os mais próximos do rei, que afirmavam que "o rei era todo em poder dela, e que o trazia enfeitiçado, pois não fazia mais que quanto ela queria” (Lopes, [s/d]: p.232). Essa ideia do "feitiço" de Leonor sobre o rei aparece em outros momentos da narrativa e sempre relacionado à afirmação de sua vontade perante o rei. Vontade e voz andam juntas (uma das características da personagem seria ser muito solta ao falar, ser muito faladora), e a afirmação de seus desejos fazia dela a mulher "cuja voz valia mais do que todos" (Lopes, [s/d]: p.376)

Tal caracterização de Leonor Teles traz consigo a caracterização de um rei fraco, um rei que cedia aos desejos da mulher e que não foi capaz de deixar herdeiros homens, trazendo um fim melancólico para a dinastia de Borgonha. Esse poder de Leonor de deixar os homens ao seu redor menos viris é manifesto no comentário que o cronista atribui à rainha ao conhecer o rei de Castela: "de mim vos digo que o homem queria eu que fosse mais homem" (Lopes, $[\mathrm{s} / \mathrm{d}]$ : p.581). E tal comentário teria sido proferido justamente em conversa com o Mestre de Avis.

O desejo de ser regente do reino e os cálculos políticos realizados pela rainha são também explicitados na narrativa. Segundo o cronista, Leonor ao perceber que o infante D. João, filho de D. Pedro com Inês de Castro, teria pretensões ao trono em caso de morte do meio irmão D. Fernando, a rainha teria o levado a assassinar sua esposa, a própria irmã de Leonor, ao acenar com a possibilidade de casamento do infante com Beatriz, o que acabou por resultar no exílio do assassino. A verdadeira intenção de Leonor seria casar a filha com o rei de Castela, de forma que pudesse ser a regente quando D. Fernando morresse: 
[A rainha] temia que falecendo por morte [o rei], que fosse o infante logo levantado por rei (...) e era desfeita de sua honra e estado: e por esquivar de todo ponto este caso havia desejo de ter sua filha casada em Castela de guisa que o era ou melhor seria se pudesse, por ficar ela regente (...) e que assim livremente se assenhoraria do reino. (Lopes, [s/d]: p.377)

Ao tornar-se regente, a rainha exerce seus direitos tal qual um rei: "usando de toda jurisdição e senhorio em quitar homenagens e apresentar igrejas, confirmando seus bons usos e costumes às vilas e cidades que lhe enviavam requerimento, como tem usança de fazer um rei quando novamente começa a reinar" (Lopes, [s/d]: p.593). De certa forma, Leonor pretende mesmo superar a eficiência dos reis, afirmando: "a mim não cumpre andar pela terra a montes e caças, como tem costume de fazer os reis, mas tenho vontade de tomar sossego nos lugares que dissestes e nesta cidade e despender meu tempo com meus oficiais e reger e sossegar o reino em verdadeira e direita justiça" (Lopes, [s/d]: 599).

Se na Crônica de D. Fernando a ênfase narrativa se dá na manifestação da vontade de Leonor, na Crônica de D. João I a coragem da rainha é diversas vezes explicitada. Segundo Lopes, a rainha teria sabido da trama para assassinar seu aliado, o conde Andeiro, e consegue evitar que a primeira tentativa tivesse êxito, pois era "mulher avisada" (Lopes, 1945: p.5). A demora para a realização de uma nova tentativa para matar Andeiro é justificada pelo cronista pelo medo que Leonor inspirava: "que se escusaram disso, quando o houve de por em obra, temendo-se da rainha, que tinha o rei de Castela por sua parte, que podia depois causar sua desonra e morte" (Lopes, 1945: p.17). Entretanto, o Mestre de Avis empreende a nova tentativa e tem êxito, com o apoio de Rui Pereira. O conde foi assassinado no cômodo ao lado de Leonor que, se de início mostra algum temor, logo recupera o controle da situação e ordena que o Mestre de Avis deixe o paço: "a rainha quando isto ouviu houve grande temor", mas em seguida dá uma ordem, "vão perguntar ao Mestre se eu ei de morrer" e diante da negativa, determina "Pois se assim é, diga-lhe que desembargue meus paços" (Lopes, 1945: p.23)

A admiração do cronista pela personagem parece grande ao afirmar "Foi mulher muito inteira e de coração cavalheiresco, buscador de maravilhosas artes, por firmeza de seu estado." Mas, em seguida, Lopes completa: "Desde que reinou, aprenderam as mulheres a ter novos jeitos com seus maridos, as mostranças duma coisa por outra mais 
perfeitamente do que se acha nos anciões tempos, que outra rainha de Portugal fizesse." (Lopes, 1945: p.36)

Apesar de o assassinato ter sido bem sucedido e a rainha ter tido que deixar Lisboa devido aos tumultos, Fernão Lopes afirma que o Mestre de Avis tinha tanto medo de Leonor que pensou em fugir para a Inglaterra: "O mestre determinou não ficar no reino e ir para a Inglaterra (...) Primeiramente ele temia muito a rainha (...) ele que a conhecia por mulher de grande coração e muito vingador de quem desprazer havia (...)"(Lopes, 1945: p. p. 40). Coração aqui tem o sentido de coragem. Coragem inclusive para a vingança. Os apelos dos da cidade de Lisboa para que o Mestre ficasse e os defendesse seguia a mesma argumentação, estavam "a mercê da rainha que conheciam por muito vingadora de vontade" (Lopes, 1945: p. 41). É justamente essa vontade de vingança que aparece na narrativa de Lopes diretamente associada à natureza feminina:

E por tanto a rainha dona Leonor por vontade feminina que geralmente é muito desejadora de vingança, usando de um grandioso coração de que natureza lhe não fora escassa, nenhuma coisa por então a seu entendimento era mais representada, que cuidar amiúde todos os modos, por que do Mestre pudesse haver cumprida emenda. (Lopes, 1945: p.44)

O pedido de ajuda que Leonor Teles faz ao rei de Castela, que acabaria por usurpar seus poderes e aprisioná-la, não aparece na narrativa de Lopes como ingenuidade da rainha. A regente teria ponderado bastante antes de sair do castelo para se encontrar com o rei de Castela: "mulher sagaz e percebida em tudo, que não tinha o coração bem seguro que o rei teria em seus feitos aquela maneira que ela desejava e queria. E receando muitas coisas e nenhuma sendo segura, que duvidava muito sair do castelo, e se por em poder do rei”. (Lopes, 1945: p.123). Ao finalmente ver-se traída pelo rei de Castela, Leonor Teles tenta ainda reagir, mas é presa pelo castelhano. A coragem da rainha é mantida até o fim, segundo o cronista: "e ela não embargando que viesse como presa,vinha bem sem medo, sem mudança que mostrasse, como mulher de grande coração que era, e entrou ela só na câmara e não outrem” (Lopes, 1945: p.159).

A única rainha das crônicas de Lopes com essa característica da coragem é D. Joana, esposa do rei de Castela D. Henrique II. O cronista narra na Crônica de D. Fernando que Henrique II procurara reaver algumas terras que estavam sob o poder de 
Portugal, propondo acordos ou usando a força. Para tanto, contava com a ajuda da rainha: "e não somente o rei com suas gentes, mas ainda a rainha sua mulher, que para isto bastante coração havia, isso mesmo se trabalhava de cercar algumas delas" (Lopes, [s/d]: p.133). A rainha guerreira de Castela aparece tão corajosa quanto a rainha portuguesa de "coração cavalheiresco, buscador de maravilhosas artes".

Observa-se que a fraqueza feminina que caracteriza a regente deposta não é a falta de coragem ou de forças para reger um reino, que, afinal, ela governava como um rei. A fraqueza de Leonor é de caráter, em especial essa "vontade feminina que em geral é muito desejadora de vingança”.

A narrativa de Rui de Pina dos acontecimentos que levaram Leonor de Aragão a perder a regência do reino é muito diversa. Se na Crônica de D. Duarte a rainha tem um perfil de mulher influente junto ao rei, na Crônica de Afonso $V$ a ênfase é numa mulher fraca e facilmente influenciável.

A Crônica de D. Duarte apresenta Leonor de Aragão como a principal responsável por influenciar o rei, a pedido do infante D. Henrique, para que fosse determinada a invasão a Tânger, que acabou resultando em derrota e aprisionamento do infante D. Fernando. Logo depois, a morte do rei, segundo Rui de Pina, teria sido fruto não apenas da peste, mas principalmente do desgosto de ter consentido que a guerra ocorresse. É possível aqui estabelecer uma comparação entre a morte de D. Fernando e a de D. Duarte, ambos enfraquecidos e influenciados por suas esposas segundo seus respectivos cronistas.

A Crônica de Afonso $V$, que é dedicada em grande parte ao período regencial, introduz o tema da fraqueza feminina e da propensão a sofrer influências já no segundo capítulo. Descrevendo as honras que o D. Pedro teria mandado fazer à rainha regente, o cronista afirma que o infante queria deixar claro sua lealdade, uma vez que sabia que não era bem quisto pela rainha:

Porque a rainha, como quer que sempre foi muito honesta, virtuosa, prudente, devota e muito amiga da vida e honra do rei seu marido, porém sempre em sua vida mostrou ao infante $\mathrm{D}$. Pedro que não lhe tinha boa vontade, e as causas porque assim fosse eram ocultas pra culpar o infante, salvo se procedessem de induzimentos alheios que em sua feminil fraqueza de ligeiro fariam impressão (Pina, 1977: p. 16) 
As qualidades da rainha Leonor de Aragão são sempre exaltadas nas crônicas de Rui de Pina, mas também sempre com a ressalva dessa sua fraqueza intrínseca à sua natureza de mulher. No capítulo seguinte, o cronista informa que "a rainha por sua guarda mandou tomar instrumentos e começou logo a usar do regimento inteiramente sem alguma pública contradição", mas acrescenta que "alguns dos seus servidores avisados e virtuosos" the deram um conselho:

\begin{abstract}
Senhora, o peso deste cargo de reger, que assim soltamente tomais, é muito grande e tal que muitos barões abastados de fortaleza de coração e de prudência o recearam. E por serdes mulher e ainda estrangeira, como quer que para isso haja em vós sã consciência e conhecidas virtudes com muito santo desejo, em caso que não houvésseis nele alguma contradição, certo duvidamos que o possas sofrer; (Pina, 1977: p.18)
\end{abstract}

A rainha exercia soltamente uma tarefa que muitos corajosos barões haviam temido. Mas por ser mulher e estrangeira teria certamente opositores. Ainda nas palavras desses servidores virtuosos, são apresentados seus opositores: "Vossa senhoria há de considerar que são neste reino três infantes, grandes príncipes e de muita autoridade e naturais da terra, que não hão de estimar por quebra e abatimento de seus estados serem regidos por mulher, especialmente não natural nem herdeira como vós sois" (Pina, 1977: p.18). É explícito o argumento de que ser regido por mulher (e estrangeira) rebaixaria o estado dos infantes. Os servidores aconselham então a rainha que "deixasse assim de vossa vontade este regimento, antes que depois o deixasse forçada, ou impedida de vossa natural fraqueza ou de outras forças maiores" (Pina, 1977: p.18). A rainha inicialmente pensa em seguir tal conselho, mas acaba mudando de ideia, pois "não faleceram logo outros, que com outras razões ao revés destas a mudaram deste propósito" (Pina, 1977: p 18). Uma série de argumentos são utilizados ao longo da crônica para que Leonor de Aragão deixasse a regência, como a suposta ilegalidade do rei deixar por testamento a indicação do regente, mas o argumento da fraqueza feminina será exaustivamente repetido.

Parece contraditório, entretanto, o fato de ser justamente o poder da regente que faz rebaixar a virilidade dos homens que a cercam. A quebra e abatimento do estado dos infantes ao serem regidos por mulher, mencionada na passagem anteriormente citada, tem seu complemento na fala do infante D. João: "porque conquanto a rainha é muito 
virtuosa e muito discreta e amiga de Deus, nunca vi maior vergonha e abatimento nosso, que sermos regidos por ela, pois é mulher e mais estrangeira” (Pina, 1977: p.46). Além desse efeito de causar abatimento e vergonha nos infantes por serem regidos por uma mulher, esse rebaixamento da virilidade masculina devido aos poderes femininos também recairia sobre seus filhos. A decisão das cortes de Lisboa de retirar a tutela da rainha sobre os filhos tem o seguinte argumento: "Primeiramente, a criação do rei ser em poder de mulher é muito danosa e sempre por isso ficará fraco e efeminado" (Pina, 1977: p.97).

O poder de Leonor Teles parece rebaixar os homens de forma proposital na narrativa de Fernão Lopes, mas Leonor de Aragão faz o mesmo na narrativa de Rui de Pina de forma involuntária, por sua natureza. Uma natureza dúbia que, sendo fraca, enfraquece os homens a seu redor.

Vimos o quanto a vontade feminina, geralmente muito desejadora de vingança segundo Lopes, tem um papel importante na caracterização de Leonor Teles e na sua insistência em permanecer regente. No caso de Leonor de Aragão, é justamente essa falta de vontade própria que a faz mudar frequentemente de opinião e acabar seguindo os maus conselheiros. No episódio em que propõe que se realize o casamento entre seu filho rei e a filha de D. Pedro, para logo em seguida mudar de ideia em benefício da neta do conde de Barcelos, o infante pede que a rainha faça uma certidão colocando por escrito o que eles haviam acordado, pois "como era prudente e discreto, não lhe esqueceu o que geralmente se crê e afirma da inconstância e pouco firmeza que muitas mulheres por sua natural condição tem quão ligeiramente se movem" (Pina, 1977: p.25).

A rainha é aconselhada pelo conde de Barcelos a reaver a certidão e "A qual como quer que como virtuosa refutasse, por não quebrar sua verdade, e mais determinação do rei D. Duarte seu marido, porém como importunada e induzida lho fizeram consentir" (Pina, 1977: p.37). Diante disso, o infante afirma, segundo o cronista: "bem creio que em suas virtudes haveria firmeza de cumprir o que prometeu e mais em causa tão justa e tão honesta, se a não movesse dela conselheiros pouco fiéis, no que lhe fazem pouco serviço;" (Pina, 1977: p.38).

Da mesma forma, nos primeiros acordos para partilhar a regência com D. Pedro, a rainha teria mudado de ideia e voltado a querer ser regente sozinha, pois teria ouvido 
seus servidores e "vencida deles, creu que em fazer tal acordo não poderia fazer coisa mais errada" (Pina, 1977: p.31).

A essa fraqueza de vontade da rainha - que era induzida, importunada, vencida somava-se a sua fraqueza física. Segundo o cronista, a regente grávida, com dores e enfermidades, teria que alternar períodos de trabalho e de repouso, de forma que alguns requerimentos demoravam a ser despachados.

\begin{abstract}
A rainha regia o reino (...) e como ela era de boa e virtuosa intenção tomava o encargo do regimento com mais trabalho e continuação do que tivera costume, nem requeria sua fraca disposição; e daí os requerimentos assim pela boa ordem que se logo deu ao ouvir deles, como por haver já dias que se não despachavam, cresciam cada vez mais; o que cada dia além de ser prenhe, lhe causava dores e enfermidades que contrariavam seu bom e verdadeiro propósito (Pina, 1977: p.42).
\end{abstract}

A fraqueza física da rainha é também base para a argumentação do infante D. João para que ela cedesse a regência ao infante D. Pedro. Segundo o cronista, D. João apresenta diversos razões para o fim da regência de Leonor de Aragão, dentre eles: "o cuidado e trabalho de reger ser incompatível às forças da rainha" (Pina, 1977: p.47).

A caracterização da personagem Leonor de Aragão como uma rainha sem vontade própria e fraca fisicamente contrasta com as ações e a tenacidade na tentativa de manutenção de sua regência narradas pelo próprio Rui de Pina. Segundo o cronista, a rainha reforça muralhas e defesas, confisca gêneros alimentícios prevendo cercos, mobiliza homens para a guerra e envia diversas cartas solicitando ajuda aos reinos de Castela e Aragão. Leonor só se rende no exílio, já esgotadas todas as suas tentativas de reaver seus direitos de regente.

\title{
Conclusões
}

O tema da fraqueza feminina, tão frequente nas fontes medievais, muitas vezes induziu os historiadores a considerar que o espaço de atuação das mulheres nos reinos do ocidente medieval era muito reduzido. Os estudos de queenship vêm procurando demonstrar que o exercício de poder da rainha, seja como consorte ou como única regente do reino, constituía uma espécie de ofício, legítimo e com atribuições que 
estavam longe de ser apenas protocolares (Earenfight, 2017). Em Portugal, a consolidação da Casa da rainha, com uma rede de servidores e terras sobre as quais a rainha obtinha ganhos e tinha ampla jurisdição, é um dos indícios desse poder legítimo (Silva, 2010). Certamente que a regência em caso de falecimento do rei fazia ampliar esses poderes da rainha para todo o reino e as disputas daí resultantes eram muitas.

Propomos aqui uma reflexão sobre o lugar da fraqueza feminina como explicação para a deposição das rainhas regentes portuguesas, Leonor Teles e Leonor de Aragão, no próprio discurso dos cronistas medievais que se dedicaram a narrar tais episódios. As diferenças das narrativas de Fernão Lopes e Rui de Pina se dão, em parte, devido à própria distância que os separa no tempo e a conjuntura em que escrevem. Lopes, primeiro cronista oficial do reino, escreve principalmente durante o reinado de D. Duarte (1433-1438) e tinha a tarefa de legitimar a dinastia que o contratara. A caracterização da regente, viúva do rei da dinastia anterior, veio, portanto, naturalmente carregada de tons sombrios. Rui de Pina, por seu turno, escreveu sobre a regência de Lonor de Aragão num período em que a consolidação dinástica estava efetuada, no reinado de D. Manuel (1495-1521), mas precisava explicar os acontecimentos que levaram à destituição de uma rainha que gerou um rei de Avis. Assim, as virtudes de Leonor de Aragão são sempre lembradas, apesar de suas fraquezas.

O tema da fraqueza feminina é muito mais elencado por Rui de Pina. Fraqueza de vontade que se traduz na inconstância e rendição às más influências, mas fraqueza também física de um corpo que engravida e sofre as dores do parto. Fraquezas que são parte da natureza feminina e das quais Leonor de Aragão não tem como fugir. Por outro lado, as razões que teriam levado Leonor Teles, na narrativa de Lopes, a perder a regência estão ligadas a características inversas à fraqueza de vontade de Leonor de Aragão. É a sua ambição e firme desejo de governar que leva à sua ruína. Vontade feminina que sempre deseja vingança. A fraqueza física também não existe em Leonor Teles, que engravidou várias vezes, mas tal fato não a impediu de ter a voz que valia mais do que todos.

Um tema correlato parece, no entanto, unir as narrativas sobre essas duas mulheres: a do poder feminino que diminui a virilidade dos homens ao seu redor. A rainha de coração cavalheiresco provoca medo e ridiculariza os homens. A rainha virtuosa e frágil envergonha aqueles que precisam se submeter a ela. Mas se era uma 
crença compartilhada a de que mulher não deveria ter regimento, segundo o discurso do doutor em leis Diogo Afonso Mangancha, transcrito por Rui de Pina, o que justificaria o fato de que os reis, diante da própria morte, regularmente indicassem suas esposas como regentes? O ocidente medieval tem diversos exemplos de mulheres que exerceram plenamente o queenship, independentemente da insistência discursiva sobre a fraqueza feminina. Leonor Teles e Leonor de Aragão não puderam fazer valer seus direitos, mas, a crer nas narrativas dos cronistas, defenderam esses direitos com todas as suas forças.

\section{Bibliografia}

BALEIRAS, Isabel de Pina. Uma rainha inesperada. Leonor Teles. Lisboa: Círculo de Leitores, 2012.

COSER, Miriam. Modelo mariano e discurso político nas crônicas de Avis. In: AMARAL, Clinio; BERRIEL, Marcelo Santiago (orgs.). Religião e religiosidade na Idade Média: poder e práticas discursivas. Rio de Janeiro: Multifoco, 2012, pp. 103118.

EARENFIGHT, Theresa. Queenship in Medieval Europe. New York: Palgrave MacMillan, 2013. . Medieval Queenship. History Compass. V. 15. 2017.

GOMES, Rita Costa. A corte dos reis de Portugal no final da Idade Média. Lindaa-Velha: Difel, 1995.

LOPES, Fernão. Crônica de D. Fernando. Lisboa: Imprensa Nacional-Casa da Moeda, [s/d].

. Crônica de D. João I. vol.1. Porto: Civilização, 1945.

. Crônica de D. João I. vol. 2. Porto: Civilização, 1949.

MATTOSO, José; SOUSA, Armindo. História de Portugal. A monarquia feudal. Lisboa: Estampa, 1992.

OLIVEIRA, Ana Rodrigues. Rainhas medievais de Portugal. Lisboa: Esfera dos Livros, 2010.

ORLANDI, Eni. Análise de Discurso. Princípios e Procedimentos. Pontes Editores: Campinas, 2015.

PINA, Rui de. Crônica de D. Duarte. Porto: Lello \& Irmão, 1977. . Crônica de D. Afonso V. vol. I Lisboa: Escriptorio, 1901. . Crônica de D. Afonso V. vol. II. Lisboa: Escriptorio, 1902. . Crônica de D. Afonso V. vol. III. Lisboa: Escriptorio, 1902.

RODRIGUES, Ana Maria. As tristes rainhas: Leonor de Aragão e Isabel de Coimbra. Lisboa: Círculo de Leitores, 2013. 
SILVA, Manuela Santos. Os primórdios da Casa das Rainhas de Portugal. In: As raízes medievais do Brasil moderno. Lisboa: Academia Portuguesa de História-Centro de História da Universidade de Lisboa, 2008, p.27-41.

A Casa e o patrimônio da Rainha de Portugal D. Filipa de Lencastre: um ponto de partida para o conhecimento da Casa das Rainhas na Idade Média. Revista Signum, n.2, v.11, 2010. Leitores, 2012.

. A rainha inglesa de Portugal: Filipa de Lancaster. Lisboa: Círculo de

\footnotetext{
${ }^{1}$ As informações biográficas sobre a rainha Leonor Teles foram retiradas principalmente de Oliveira, 2010 e Rodrigues, 2013.

${ }^{2}$ As informações biográficas sobre a rainha Leonor de Aragão foram retiradas principalmente de Oliveira, 2010 e Baleiras, 2012.

${ }^{3}$ Entendemos aqui discurso tal como definido por Orlandi, 2015.

${ }^{4}$ As passagens referentes às citações das crônicas foram por mim atualizadas para o português moderno, no intuito de facilitar a leitura do público não especializado.
} 